\title{
ERRATUM
}

\section{Centred and staggered arrangements of tidal turbines - ERRATUM}

\author{
S. Draper and T. Nishino \\ doi:10.1017/jfm.2013.593, Published by Cambridge University Press, \\ 17 December 2013
}

In Draper \& Nishino (2014) an incorrect file for figure 10 was published. The Publisher and authors apologise to the readers for this error. The correct figure is shown below.
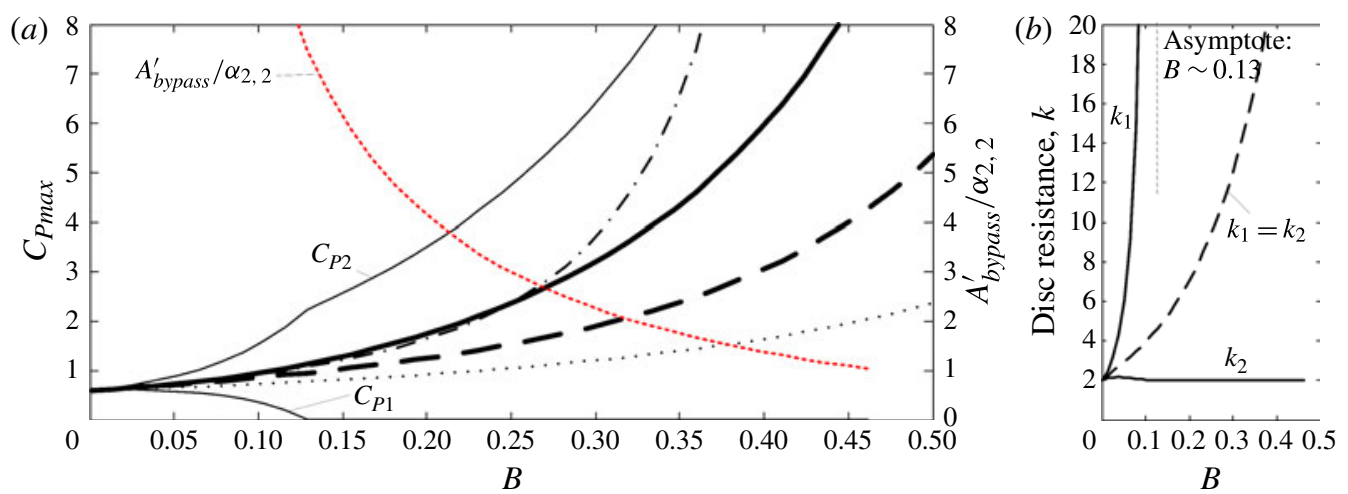

FIgURE 10. (a) Local maximum in power coefficient (averaged across all discs) as a function of blockage ratio. Thick solid line: two staggered discs (with no constraint on local resistance); thick dashed line: two staggered discs with $k=k_{1}=k_{2}$ (see $\S 4.1$ ); dash-dotted line: single disc with twice the blockage (representative of two discs in the same plane); dotted line: two separate discs (representative of widely spaced discs); thin solid lines: power coefficients for the front and back discs adding to give thick solid line. (b) Solid lines: disc resistances associated with thick and thin solid lines in $(a)$; dashed line: disc resistance associated with thick dashed line in $(a)$.

\section{REFERENCE}

Draper, S. \& Nishino, T. 2014 Centred and staggered arrangements of tidal turbines. J. Fluid Mech. 739, 72-93. 